\title{
Prevalence and management of back pain in adolescent idiopathic scoliosis patients: A retrospective study
}

\author{
Jean Théroux DC MSc ${ }^{1}$, Sylvie Le May RN PhD ${ }^{1,2}$, Carole Fortin PHT PhD ${ }^{1,4}$, Hubert Labelle MD $\mathrm{D}^{1,3}$
}

\begin{abstract}
J Théroux, S Le May, C Fortin, H Labelle. Prevalence and management of back pain in adolescent idiopathic scoliosis patients: A retrospective study. Pain Res Manag 2015;20(3):153-157.
\end{abstract}

BACKGROUND: Back pain (BP) has often been associated with adolescent idiopathic scoliosis (AIS), which is a three-dimensional deviation of the vertebral column. In adolescents, chronic pain appears to be a predictor of health care utilization and has a negative impact on physical, psychological and family well-being. In this population, BP tends to be persistent and may be a predictor of BP in adulthood.

OBJECTIVE: To document the prevalence and management of $\mathrm{BP}$ in AIS patients.

METHODS: A retrospective chart review of AIS patients who were referred to Sainte-Justine University Teaching Hospital (Montreal, Quebec) from 2006 to 2011 was conducted.

RESULTS: A total of 310 randomly selected charts were reviewed. Nearly one-half of the patients $(47.3 \%)$ mentioned that they experienced BP, most commonly in the lumbar (19.7\%) and thoracic regions (7.7\%). The type of BP was documented in only $36 \%(n=112)$ of the charts. Pain intensity was specified in only $21 \%(n=65)$ of the charts. In approximately $80 \%(n=248)$ of the charts, no pain management treatment plan was documented.

CONCLUSIONS: The prevalence of BP was moderately high among the present sample of adolescents with AIS. An improved system for documenting BP assessment, type, treatment plan and treatment effectiveness would improve pain management for these patients.

Key Words: Adolescent idiopathic scoliosis; Back pain; Chronic pain; Pain management; Prevalence

B ack pain in the adolescent population has generally been considered to be much less prevalent than in adults, and has often been associated with severe pathological conditions (eg, spondylolysis, spondylolisthesis, inflammatory diseases) requiring in-depth investigation (1-4). Fortunately, this condition has been widely studied over the past decade $(5-14)$. The reported prevalence of back pain varies considerably ( $7 \%$ to $58 \%$ ) and appears to be influenced by a number of factors such as age, sample size, the definition of low back pain used, recall period and data extraction strategies (15). A recent meta-analysis by Calvo-Munoz et al (16) investigating the prevalence of low back pain among children and adolescents reported a mean prevalence of nearly $40 \%$ in healthy adolescents. Studies have reported at least a 33\% recurrence rate of episodic back pain in adolescents with back pain $(7,10)$. Long-lasting back pain in children or adolescents appears to be a predictor of adult back pain (17-21). Unfortunately, back pain is experienced by most adults during their lifetime $(22-24)$ and is the second most common reason that adults consult a primary care physician $(23,25)$. Back pain in adolescents appears to be a predictor of increased health care utilization, and

\section{La prévalence et la prise en charge des douleurs dorsales chez les adolescents ayant une scoliose idiopathique : une étude rétrospective}

HISTORIQUE : Les douleurs dorsales (DD) s'associent souvent aux adolescents ayant une scoliose idiopathique (ASI), qui est une déviation tridimensionnelle de la colonne vertébrale. Chez les adolescents, la douleur chronique semble être prédictive de l'utilisation des soins de santé et nuit au bien-être physique, psychologique et familial. Au sein de cette population, la DD a tendance à être persistante et peut être prédictive de DD à l'âge adulte.

OBJECTIF : Attester la prévalence et la prise en charge de la DD chez les ASI

MÉTHODOLOGIE : Les chercheurs ont réalisé une analyse des dossiers d'ASI orientés vers le Centre hospitalier universitaire Sainte-Justine entre 2006 et 2011.

RÉSULTATS : Les chercheurs ont analysé 300 dossiers sélectionnés au hasard. Près de la moitié des patients $(47,3 \%)$ indiquaient souffrir de DD, surtout dans les régions lombaire $(19,7 \%)$ et thoracique $(7,7 \%)$. Le type de DD n'était consigné que dans $36 \%(\mathrm{n}=112)$ des dossiers, et l'intensité de la douleur, dans $21 \%(n=65)$ des dossiers. Dans environ $80 \%(n=248)$ des dossiers, aucun plan de traitement de la douleur n'était consigné.

CONCLUSIONS : La prévalence de DD était modérément élevée dans le présent échantillon d'ASI. Un meilleur système pour consigner l'évaluation, le type, le plan de traitement et l'efficacité du traitement de la DD améliorerait la prise en charge de ces patients.

${ }^{1}$ Research Center, Sainte-Justine University Hospital Center; ${ }^{2}$ Faculty of Nursing; ${ }^{3}$ Faculty of Medicine; ${ }^{4}$ School of rehabilitation, Faculty of Medicine, University of Montreal, Montreal, Quebec

Correspondence: Dr Sylvie Le May, CHU Sainte-Justine Research Centre, Étage A, Bloc 7, 3175 Côte-Ste-Catherine, Montréal, Québec H3T 1C5. Telephone 514-345-4931 ext 4938, fax 450-621-3960, e-mail sylvie.lemay@umontreal.ca

appears to have a negative impact on physical, psychological and family well-being $(12,26,27)$.

Spinal asymmetry or scoliosis is a major risk factor for back pain in adolescents (14,28-31). The most common type of scoliosis in this population is adolescent idiopathic scoliosis (AIS) (32), which is defined by the Scoliosis Research Society (33) as a three-dimensional deviation of the spine of unknown origin associated with a Cobb angle $>10^{\circ}$ (34). The estimated prevalence of AIS is between 2\% and 3\% (35), and some studies have reported that back pain is twice as prevalent in AIS patients compared with nonscoliosis patients $(29,36)$. Joncas et al (36) prospectively evaluated 239 AIS patients (mean age 14.4 years) presenting with double right thoracic-left lumbar scoliosis. More than one-half of their sample (54\%) experienced back pain, most commonly in the lumbar region (30\%) followed by the thoracic region $(12 \%)$. The overall mean $( \pm$ SD) pain intensity was $49.4 \pm 20 \mathrm{~mm}$ on a visual analogue scale ranging from zero to 100 , which is considered to represent moderate-intensity pain. In contrast, Sato et al (29) conducted a largescale cross-sectional epidemiological study in which all children in a defined area of Japan were asked to complete a take-home questionnaire

\footnotetext{
open Access

This open-access article is distributed under the terms of the Creative Commons Attribution Non-Commercial License (CC BY-NC) (http:// creativecommons.org/licenses/by-nc/4.0/), which permits reuse, distribution and reproduction of the article, provided that the original work is properly cited and the reuse is restricted to noncommercial purposes. For commercial reuse, contact support@pulsus.com
} 
TABLE 1

Scoliosis curve presentation $(n=310)$

\begin{tabular}{lccc}
\hline & All $\mathbf{( n = 3 1 0 )}$ & Girls $\mathbf{( n = 2 7 8 )}$ & Boys $\mathbf{( n = 3 2 )}$ \\
\hline Single curve (59.4\%) & & & \\
Cervicothoracic & $1(0.32)$ & $0(0)$ & $1(3.1)$ \\
Thoracic & $66(21.3)$ & $61(21.9)$ & $5(15.6)$ \\
Thoracolumbar & $98(31.6)$ & $87(31.3)$ & $11(34.4)$ \\
Lumbar & $19(6.1)$ & $15(5.4)$ & $4(12.5)$ \\
$\quad$ Total & & $163(58.6)$ & $21(65.6)$ \\
Double curve (36.4\%) & & & \\
$\quad$ Thoracic-thoracolumbar & $67(21.6)$ & $59(21.2)$ & $8(25)$ \\
$\quad$ Thoracic-lumbar & $46(14.8)$ & $43(15.5)$ & $3(9.4)$ \\
$\quad$ Total & & $102(36.7)$ & $11(34.4)$ \\
Triple curve (4.2\%) & $13(4.2)$ & $13(4.7)$ & $0(0)$ \\
$\quad$ Total & & $13(4.7)$ & $0(0)$ \\
\hline
\end{tabular}

Data presented as $n$ (\%)

TABLE 2

Narrated pain

\begin{tabular}{lccc}
\hline & All $\mathbf{( n = 3 1 0 )}$ & Girls $(\mathbf{n = 2 7 8 )}$ & Boys $(\mathbf{n}=\mathbf{3 2})$ \\
\hline Generalized back pain & $57(18.4)$ & $51(18.3)$ & $6(18.8)$ \\
Nonlimiting pain & $64(20.65)$ & $61(21.9)$ & $3(9.4)$ \\
Occasional pain & $38(12.3)$ & $34(12.2)$ & $4(12.5)$ \\
Limiting pain & $12(3.87)$ & $11(4.0)$ & $1(3.1)$ \\
\hline
\end{tabular}

Data presented as $n$ (\%)

regarding current and past back pain occurrences. All of the participants $(n=43,630$ students between nine and 15 years of age $)$ were screened for scoliosis. The authors reported a $58.8 \%$ prevalence of back pain in scoliotic patients compared with $33 \%$ in nonscoliotic patients. This prevalence was similar to that reported by Joncas et al (36). When adjusted for sex and school grade, the scoliotic group had twice the prevalence of back pain (OR 2.10 [95\% CI 1.18 to 3.72]; $\mathrm{P}=0.012$ ), which lasted longer ( $36 \%$ versus $7.7 \%$ ) and occurred more frequently $(83.9 \%$ versus $60.1 \%$ ) compared with the nonscoliotic group.

These findings on back pain in children and adolescents have recently led researchers to study different approaches for its prevention and treatment (37-39). Compared with adults (40-44), back pain management initiatives in children and adolescents have mainly focused on the effectiveness of exercises $(45,46)$, back school $(47,48)$ and spinal manipulation $(47,49)$. A thorough review of the literature did not find any clinical guidelines regarding back pain management in adolescents. The implementation of clinical guidelines remains a challenge in day-to-day clinical practice $(50,51)$. The treatments usually suggested for the management of back pain in adults are: shortterm use of medication (acetaminophen) and spinal manipulation therapy; supervised exercises; cognitive-behavioural therapy; and a multidisciplinary approach that may consist of back school, workplace visits by an occupational therapist, etc $(52-56)$. To date, no evidencebased recommendations for back pain treatments in children or adolescents with AIS have been published. The aim of the present retrospective study, therefore, was to document the prevalence and management of back pain in AIS patients.

\section{METHODS}

Patient charts were selected from the Centre hospitalier universitaire Sainte-Justine (Montreal, Quebec) orthopedic department Scoliosys ${ }^{\circledR}$ database. This database contains $>4000$ electronic charts of patients seen in the orthopedic department. From this database, 657 charts of patients with a diagnosis of AIS were randomly selected. These charts were then reviewed according to the inclusion criteria, which were: adolescents 10 to 17 years of age who had a diagnosis of idiopathic scoliosis between the years 2006 and 2011; and documentation of back pain, either directly from the attending physicians, a medical reference
TABLE 3

Pain management

\begin{tabular}{lcc}
\hline & Girls & Boys \\
\hline Medication & $15(5.4)$ & $1(3.1)$ \\
Physical therapy & $38(13.7)$ & $4(12.5)$ \\
Nonspecific exercises & $3(1.1)$ & $0(0)$ \\
Other & $3(1.1)$ & $0(0)$ \\
No management documented & $219(78.8)$ & $27(84.4)$ \\
\hline
\end{tabular}

Data presented as n (\%)

(family physicians, pediatricians or physical therapists) or letters from parents. Exclusion criteria were: previous surgery (spinal fusion); and any pathological spinal anomalies, such as spondylolisthesis, that could be associated with back pain.

Data were collected regarding age, sex, menarche status, Cobb angle (the measure used to quantify the magnitude of spinal deformities), type of scoliosis (single or double curve) and scoliosis treatment recommendations (observation, brace or surgery). In addition, the charts were searched for pain-specific factors, including pain assessment, site, intensity, treatment and clinical efficacy of treatment, if documented.

\section{Statistical analysis}

Data were analyzed using descriptive statistics (frequency and distribution). Fisher's exact test was used to verify any association between back pain, type of scoliosis and Cobb angle.

\section{Patient characteristics}

\section{RESULTS}

A total of 310 patient charts met the inclusion criteria. The charts were mainly from female patients (89.7\%). Mean ( \pm SD) ages of girls and boys were $13.89 \pm 1.81$ years and $14.47 \pm 1.46$ years, respectively. Most girls (78.4\%) had already reached menarche at the time of their first visit. Most patients had a Cobb angle $<40^{\circ}$ (84.2\%). Overall, single curves were more prevalent $(59.4 \%)$ than double, while the most prevalent areas of involvement were thoracic $(21.3 \%)$ and thoracolumbar (31.6\%) (Table 1). Among adolescents who presented with a double curve, the thoracic-thoracolumbar curve (21\%) and the thoracic-lumbar curve $(14.8 \%)$ were the most recorded patterns of presentation. Bracing was recommended for $22.3 \%$ of the patients, with a higher percentage among girls (23\%).

\section{Back pain}

Nearly one-half of the patients $(47.3 \%)$ had chart-documented back pain, either through a pain score or narrative, or reported by their family. The most painful area for both sexes was the lumbar region $(22.6 \%)$. Table 2 shows the narratives used to describe back pain in the charts that were reviewed. Use of these narratives made it difficult to properly identify the site of pain. In fact, the association between the expression of pain and a specific spinal area was documented in $<40 \%$ of the charts reviewed. Pain intensity was specified in only $21 \%$ of charts and was described as mild in $9.4 \%$ and moderate in $11 \%$. Severe pain was documented in only $1 \%$ of the charts.

Whether there was a relationship between the site of back pain and the type of scoliosis was also investigated. A statistically significant association was found between thoracic pain and thoracic scoliosis $(\mathrm{P}=0.015)$. When there was documentation of thoracic scoliosis in the chart, there was an OR of 3.733 (95\% CI 1.312 to 10.623 ) that the patient would complain of thoracic pain. Finally, there was no statistically significant difference between the intensity of pain and the severity of the Cobb angle.

\section{Pain management}

Table 3 lists the pain treatments according to sex. Pain management was documented in only $20 \%$ of charts. The main treatments identified for back pain management were analgesic or anti-inflammatory medication (5.2\%), physical therapy $(13.5 \%)$ and exercises (1\%). No 
information regarding the clinical efficacy of each of these treatments was found in the charts.

\section{DISCUSSION}

Our study demonstrates that back pain is prevalent in AIS patients and that its management is often suboptimal. When documented, back pain intensity was reported as mild or moderate, most commonly affecting the lumbar area. Narrative descriptions of the pain were often used in the charts that were reviewed.

Few studies have evaluated back pain in AIS patients (29,36,57-64). Among these, conflicting results regarding back pain prevalence were observed, and back pain management was not addressed. Furthermore, only two studies specifically investigated back pain and AIS $(36,58)$ and they, too, failed to address pain management. A retrospective study by Ramirez et al (58) evaluated the charts of 2442 adolescent patients who were seen in a scoliosis clinic. The back pain prevalence was $32 \%$. The authors concluded that this was similar to the rate observed in nonscoliotic adolescents. Furthermore, they did not investigate the relationship between the occurrence of pain and the type of curve. The wide age range in the Ramirez et al (58) study may explain the differences in prevalence observed between their study and the present study.

Joncas et al (36) prospectively evaluated 239 AIS patients presenting with double right thoracic-left lumbar scoliosis. More than one-half $(54 \%)$ of their sample experienced back pain of moderate intensity, and the most commonly reported area of pain was the lumbar region. These results are similar to those of the present study.

Among the other studies that investigated the association between back pain and AIS, three focused on health-related quality of life issues; in these, back pain was estimated. Those studies assessed back pain prevalence in an adult population that had previously received a diagnosis of AIS $(57,63,64)$ as adolescents. The other three studies evaluated back pain in adolescents who were surgical candidates, which usually implies a greater Cobb angle $(59,61,62)$; however, these studies failed to address the issue of management. Sato et al (29) conducted a large-scale cross-sectional epidemiological study in which 43,630 students were screened for scoliosis. The authors reported a back pain prevalence of $58.8 \%$ in the scoliotic patients. In this group, back pain lasted longer and was associated with more frequent episodes. Although this prevalence is similar to that reported by Joncas (36), it is somewhat higher than that documented in the present study $(47.3 \%)$. This difference may have occurred because Sato et al (29) did not report the curve severity in the scoliosis group and may, therefore, have included patients with a curvature of $<10^{\circ}$ and those requiring surgical intervention (higher Cobb angle).

\section{Back pain management}

Over the past decade, many clinical guidelines have been introduced to help physicians manage back pain $(52,54-56,65,66)$. Those guidelines were eventually refined (66), and now the majority provide recommendations on the assessment and management of acute or chronic back pain $(54,66)$. Nonetheless, the recommendations remain confusing regarding the implementation of the best pain management strategies, most likely because effective back pain treatment involves a multidisciplinary approach, which is lacking in most guidelines $(66,67)$. The most common back pain management interventions are exercise therapy, multidisciplinary treatment (combined inpatient exercises, physical therapy, home exercises and usual care), combined physical and psychological interventions, short-term use of medication (acetaminophen, nonsteroidal anti-inflammatory drugs or opioid analgesics) and spinal manipulation $(42,52,56,66,67)$. Furthermore, many guidelines now consider patients' expectations, beliefs and preferences (66). Unfortunately, the currently available guidelines were developed for adults ( $>18$ years of age). Although pain management was not extensively recommended in the charts reviewed, the recommendations we did find were consistent with those suggested in the adult guidelines. A thorough review of the literature did not yield any specific guidelines or studies recommending guidelines for back pain management in adolescents. We believe that adult guidelines may not be appropriately extrapolated to back pain management in adolescents and children. The studies published over the past decade mainly focused on the prevalence and risk factors for back pain rather than its management $(1-3,5-9,11,13,14,16,20,21,28)$.

A recent meta-analysis of physical therapy for low back pain in nonscoliotic children and adolescents (68) concluded that a combination of therapeutic physical conditioning and manual therapy was the most effective approach for back pain in that population, though definitive conclusions were impossible due to the small number of studies (8) as well as control-group and other methodological limitations. Another systematic review (69) noted the absence of rigorous clinical trials investigating the efficacy of spinal manipulation for back pain management in children and adolescents.

Notably, since September 2012, the CHU Sainte Justine pediatric teaching hospital in Montreal, Quebec, has implemented a physical therapy referral program for AIS patients with concomitant back pain. This program has yet to be evaluated.

\section{Strengths and limitations}

Our study had several limitations. First, the data were obtained from only one pediatric hospital centre; thus, it is not possible to extrapolate our results to other hospitals treating adolescent scoliosis patients. Second, we collected data retrospectively; therefore, our results are limited by the several charts that had incomplete documentation. Third, it is possible that patients reported back pain that was not documented in the chart. If this was, in fact, the case, the back pain prevalence would be higher than we reported.

\section{CONCLUSION}

The results of the present study suggest that back pain is a condition experienced by many AIS patients and that pain management is suboptimal. Adolescent idiopathic scoliosis patients are often directly referred to a paediatric orthopaedic surgeon, who should routinely assess pain with a validated self-reported scale to record objectively the intensity and location of pain (70). When deemed necessary, functional measures should be used to assess progress, especially if pain management is recommended. These measures should be performed and documented by the attending physician managing the patient's pain as well as by other health professionals (nurses, physical therapist, chiropractor, etc). Scores and observations should be used to assess progress and treatment efficacy. Optimal back pain management is important, especially in children and adolescents, in whom the pain may be a precursor of adult back pain. Additional research regarding back pain management in this population is required. Future studies should look at back pain management with AIS patients in multiple diversified clinical centres to better understand its occurrence and management and suggest proper and personalized interventions.

\section{REFERENCES}

1. Davis PJC, Williams HJ. The investigation and management of back pain in children. Arch Dis Child Educ Pract Ed 2008;93:73-83.

2. Haidar R, Saad S, Khoury NJ, Musharrafieh U. Practical approach to the child presenting with back pain. Eur J Pediatr 2011;170:149-56.

3. Balague F, Troussier B, Salminen J. Non-specific low back in children and adolescents: Risk factors. Eur Spine J 1999;8:429-38.

4. Altaf F, Heran MKS, Wilson LF. Back pain in children and adolescents. Bone Joint J 2014;96-B:717-23.

5. Jones MA, Stratton G, Reilly T, Unnithan VB. A school-based survey of recurrent non-specific low-back pain prevalence and consequences in children. Health Educ Res 2004;19:284-9.

6. Mohseni-Bandpei MA, Bagheri-Nesami M, Shayesteh-Azar M. Nonspecific low back pain in 5000 Iranian school-age children. J Pediatr Orthop 2007;27:126-9.

7. Jones GT, Macfarlane GJ. Predicting persistent low back pain in schoolchildren: A prospective cohort study. Arthritis Care Res (Hoboken) 2009;61:1359-66.

8. Pellise F, Balague F, Rajmil L, et al. Prevalence of low back pain and its effect on health-related quality of life in adolescents. Arch Pediatr Adolesc Med 2009;163:65-71. 
9. Yao W, Mai X, Luo C, Ai F, Chen Q. A cross-sectional survey of nonspecific low back pain among 2083 schoolchildren in China. Spine (Phila Pa 1976) 2011;36:1885-90.

10. Van Gessel H, Gaßmann J, Kröner-Herwig B. Children in pain: Recurrent back pain, abdominal pain, and headache in children and adolescents in a four-year-period. J Pediatr 2011;158:977-83.

11. Kjaer P, Wedderkopp N, Korsholm L, Leboeuf-Yde C. Prevalence and tracking of back pain from childhood to adolescence. BMC Musculoskel Disord 2011;12:98.

12. O'Sullivan P, Beales D, Smith A, Straker L. Low back pain in 17 year olds has substantial impact and represents an important public health disorder: A cross-sectional study. BMC Public Health 2012;12:100

13. Trigueiro MJ, Massada L, Garganta R. Back pain in Portuguese schoolchildren: Prevalence and risk factors. Eur J Public Health 2013;23:499-503

14. Wirth B, Knecht C, Humphreys K. Spine day 2012: Spinal pain in Swiss school children - epidemiology and risk factors. BMC Pediatrics 2013;13:159.

15. Smith DRL, Peter A. Back pain in the young: A review of studies conducted among school children and university students. Curr Pediatr Rev 2007;3:69-77.

16. Calvo-Munoz I, Gomez Conesa A, Sanchez-Meca J. Prevalence of low back pain in children and adolescents: A meta-analysis. BMC Pediatr 2013;13:14

17. Harreby M, Neergaard K, Hesselse G, Kjer J. Are radiologic changes in the thoracic and lumbar spine of adolescents risk factors for low back pain in adults? A 25-year prospective cohort study of 640 school children. Spine (Philadelphia, Pa 1976) 1995;20:2298-302.

18. Brattberg G. Do pain problems in young school children persist into early adulthood? A 13-year follow-up. Eur J Pain 2004;8:187-99.

19. Hestbaek L, Leboeuf Yde C, Kyvik K, Manniche C. The course of low back pain from adolescence to adulthood: Eight-year follow-up of 9600 twins. Spine (Philadelphia, Pa 1976) 2006;31:468-72.

20. Jeffries L, Milanese S, Grimmer-Somers K. Epidemiology of adolescent spinal pain. A systematic overview of the research literature. Spine (Phila Pa 1976) 2007;32:2630-7.

21. Mikkelsson M, El-Metwally A, Kautiainen H, Auvinen A, Macfarlane GJ, Salminen JJ. Onset, prognosis and risk factors for widespread pain in schoolchildren: A prospective 4-year follow-up study. Pain 2008;138:681-7.

22. Hoy D, March L, Brooks P, et al. Measuring the global burden of low back pain. Best Pract Res Clin Rheumatol 2010;24:155-65.

23. Andersson GB. Epidemiological features of chronic low-back pain. Lancet 1999;354:581-5.

24. Hestbaek L, Leboeuf-Yde C, Manniche C. Low back pain: What is the long-term course? A review of studies of general patient populations. Eur Spine J 2003;12:149-65.

25. Hart LG, Deyo RA, Cherkin DC. Physician office visits for low back pain. Frequency, clinical evaluation, and treatment patterns from a U.S. national survey. Spine (Phila Pa 1976) 1995;20:11-9.

26. O'Sullivan P, Beales D, Jensen L, Murray K, Myers T. Characteristics of chronic non-specific musculoskeletal pain in children and adolescents attending a rheumatology outpatients clinic: A crosssectional study. Pediatr Rheumatol Online J 2011;9:3

27. Jastrowski Mano KE, Khan KA, Ladwig RJ, Weisman SJ. The impact of pediatric chronic pain on parents' health-related quality of life and family functioning: Reliability and validity of the PedsQL 4.0 Family Impact Module. J Pediatr Psychol 2011;36:517-27.

28. Kovacs F, Gestoso M, del Real M, Lopez J, Mufraggi N, Mendez J. Risk factors for non-specific low back pain in schoolchildren and their parents: A population based study. Pain 2003;103:259-68.

29. Sato T, Hirano T, Ito T, et al. Back pain in adolescents with idiopathic scoliosis: Epidemiological study for 43,630 pupils in Niigata City, Japan. Eur Spine J 2011;20:274-9.

30. Kaspiris A, Grivas T, Zafiropoulou C, Vasiliadis E, Tsadira O. Nonspecific low back pain during childhood: A retrospective epidemiological study of risk factors. J Clin Rheumatol 2010;16:55-60.

31. Nissinen M, Heliovaara M, Seitsamo J, Alaranta H, Poussa M. Anthropometric measurements and the incidence of low back pain in a cohort of pubertal children. Spine (Phila Pa 1976) 1994;19:1367-70.

32. Hresko MT. Clinical practice. Idiopathic scoliosis in adolescents. N Engl J Med 2013;368:834-41.

33. Wong HK, Tan KJ. The natural history of adolescent idiopathic scoliosis. Indian J Orthopaed 2010;44:9-13.
34. Cobb JR. Outline for the study of scoliosis. The American Academy of Orthopaedic Surgeons, instructional course lecture 1948;5:261-75.

35. Weinstein S, Dolan L, Cheng J, Danielsson A, Morcuende J. Adolescent idiopathic scoliosis. Lancet 2008;371:1527-37.

36. Joncas J, Labelle H, Poitras B, Duhaime M, Rivard CH, Le Blanc R. [Dorso-lumbal pain and idiopathic scoliosis in adolescence]. Ann Chir 1996;50:637-40.

37. Cardon G, Balagué F. Low back pain prevention's effects in schoolchildren. What is the evidence? Eur Spine J 2004;13:663-79.

38. Cardon G, de Clercq D, Geldhof E, Verstraete S, de Bourdeaudhuij I. Back education in elementary schoolchildren: The effects of adding a physical activity promotion program to a back care program. Eur Spine J 2007;16:125-33.

39. Cardon G, De Clercq DLR, De Bourdeaudhuij IMM. Back education efficacy in elementary schoolchildren: A 1-year follow-up study. Spine (Philadelphia, Pa 1976) 2002;27:299-305.

40. Bronfort G, Haas M, Evans R, Leininger B, Triano J. Effectiveness of manual therapies: The UK evidence report. Chiropr Osteopat 2010;18:3.

41. van Middelkoop M, Rubinstein SM, Kuijpers T, et al. A systematic review on the effectiveness of physical and rehabilitation interventions for chronic non-specific low back pain. Eur Spine J 2011;20:19-39.

42. van Middelkoop M, Rubinstein SM, Verhagen AP, Ostelo RW, Koes BW, van Tulder MW. Exercise therapy for chronic nonspecific low-back pain. Best Pract Res Clin Rheumatol 2010;24:193-204.

43. Scholten-Peeters G, Thoomes E, Konings S, et al. Is manipulative therapy more effective than sham manipulation in adults?: A systematic review and meta-analysis. Chiropr Man Therap 2013;21:34.

44. Kuijpers T, van Middelkoop M, Rubinstein SM, et al. A systematic review on the effectiveness of pharmacological interventions for chronic non-specific low-back pain. Eur Spine J 2011;20:40-50.

45. Jones M, Stratton G, Reilly T, Unnithan V. The efficacy of exercise as an intervention to treat recurrent nonspecific low back pain in adolescents. Pediatr Exerc Sci 2007;19:349-59.

46. Fanucchi G, Stewart A, Jordaan R, Becker P. Exercise reduces the intensity and prevalence of low back pain in 12-13 year old children: A randomised trial. Aust J Physiother 2009;55:97-104.

47. Ahlqwist A, Hagman M, Kjellby Wendt G, Beckung E. Physical therapy treatment of back complaints on children and adolescents. Spine (Philadelphia, Pa 1976) 2008;33:E721-E7.

48. Ahlqwist A, Sllfors C. Experiences of low back pain in adolescent in relation to physiotherapy intervention. Int J Qual Stud Health Well-being 2012;7.

49. Hestbaek L, Stochkendahl MJ. The evidence base for chiropractic treatment of musculoskeletal conditions in children and adolescents: The emperor's new suit? Chiropr Osteopat 2010;18:15.

50. Cabana MD, Rand CS, Powe NR, et al. Why don't physicians follow clinical practice guidelines? A framework for improvement. JAMA 1999;282:1458-65.

51. Chenot J-Fo, Scherer M, Becker A, et al. Acceptance and perceived barriers of implementing a guideline for managing low back in general practice. Implementation Sci 2008;3:7-

52. Dagenais S, Tricco AC, Haldeman S. Synthesis of recommendations for the assessment and management of low back pain from recent clinical practice guidelines. Spine J 2010;10:514-29.

53. Chou R. Low back pain (chronic). BMJ Clin Evid 2010;2010.

54. Chou R, Qaseem A, Snow V, et al. Diagnosis and treatment of low back pain: A joint clinical practice guideline from the American College of Physicians and the American Pain Society. Ann Intern Med 2007;147:478-91.

55. van Tulder M, Becker A, Bekkering T, et al. Chapter 3. European guidelines for the management of acute nonspecific low back pain in primary care. Eur Spine J 2006;15(Suppl 2):S169-91.

56. Koes BW, van Tulder M, Lin CW, Macedo LG, McAuley J, Maher C. An updated overview of clinical guidelines for the management of non-specific low back pain in primary care. Eur Spine J 2010;19:2075-94.

57. Mayo NE, Goldberg MS, Poitras B, Scott S, Hanley J. The Ste-Justine Adolescent Idiopathic Scoliosis Cohort Study. Part III: Back pain. Spine (Phila Pa 1976) 1994;19:1573-81.

58. Ramirez N, Johnston CE, Browne RH. The prevalence of back pain in children who have idiopathic scoliosis. J Bone Joint Surg Am 1997;79:364-8. 
59. Pratt R, Burwell RG, Cole A, Webb J. Patient and parental perception of adolescent idiopathic scoliosis before and after surgery in comparison with surface and radiographic measurements. Spine (Philadelphia, Pa 1976) 2002;27:1543-50.

60. Sato T, Ito T, Hirano T, et al. Low back pain in childhood and adolescence: Assessment of sports activities. Eur Spine J 2011;20:94-9.

61. Smorgick Y, Mirovsky Y, Baker KC, Gelfer Y, Avisar E, Anekstein Y. Predictors of back pain in adolescent idiopathic scoliosis surgical candidates. J Pediatr Orthop 2013;33:289-92.

62. Landman Z, Oswald T, Sanders J, Diab M, Spinal Deformity Study G. Prevalence and predictors of pain in surgical treatment of adolescent idiopathic scoliosis. Spine (Phila Pa 1976) 2011;36:825-9.

63. Weinstein SL, Zavala DC, Ponseti IV. Idiopathic scoliosis: Long-term follow-up and prognosis in untreated patients. J Bone Joint Surg Am 1981;63:702-12.

64. Danielsson AJ, Nachemson AL. Back pain and function 22 years after brace treatment for adolescent idiopathic scoliosis: A case-control study-part I. Spine (Phila Pa 1976) 2003;28:2078-85; discussion 86.

65. Koes BW, van Tulder MW, Ostelo R, Kim Burton A, Waddell G. Clinical guidelines for the management of low back pain in primary care: An international comparison. Spine (Phila Pa 1976) 2001;26:2504-13; discussion 13-4.

66. Pillastrini P, Gardenghi I, Bonetti F, et al. An updated overview of clinical guidelines for chronic low back pain management in primary care. Joint Bone Spine 2012;79:176-85.

67. Balagué F, Mannion AF, Pellisé F, Cedraschi C. Non-specific low back pain. Lancet 2012;379:482-91.

68. Calvo-Munoz I, Gomez Conesa A, Safnchez-Meca J. Physical therapy treatments for low back pain in children and adolescents: A meta-analysis. BMC Musculoskel Disord 2013;14:55-

69. Gleberzon B, Arts J, Mei A, McManus E. The use of spinal manipulative therapy for pediatric health conditions: A systematic review of the literature. J Can Chiropr Assoc 2012;56:128-41.

70. Stinson JN, Kavanagh T, Yamada J, Gill N, Stevens B. Systematic review of the psychometric properties, interpretability and feasibility of self-report pain intensity measures for use in clinical trials in children and adolescents. Pain 2006;125:143-57. 


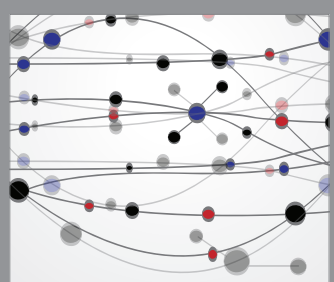

The Scientific World Journal
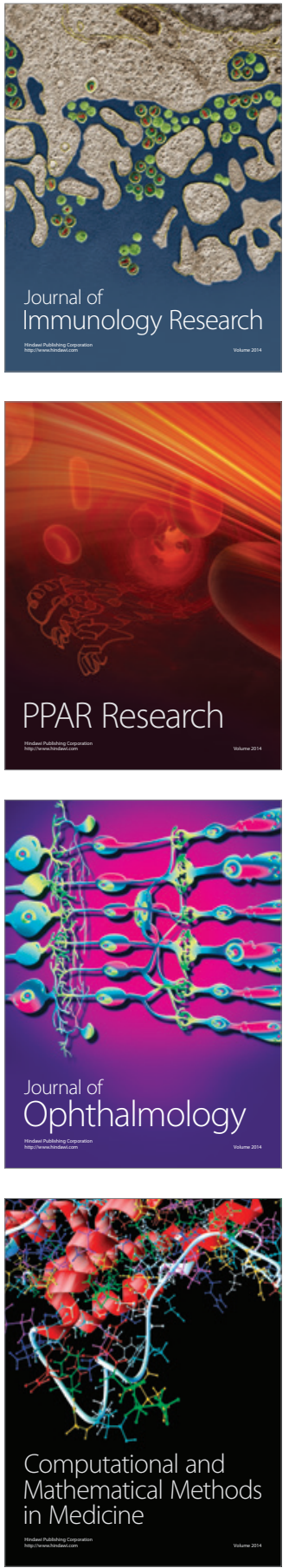

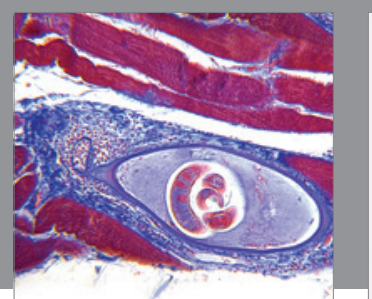

Gastroenterology Research and Practice

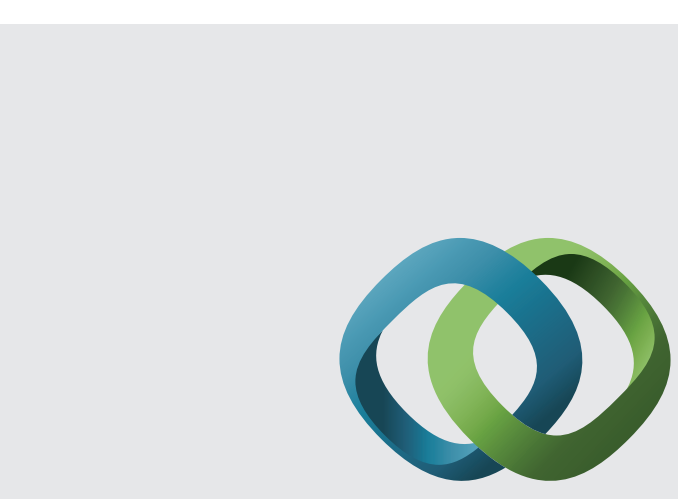

\section{Hindawi}

Submit your manuscripts at

http://www.hindawi.com
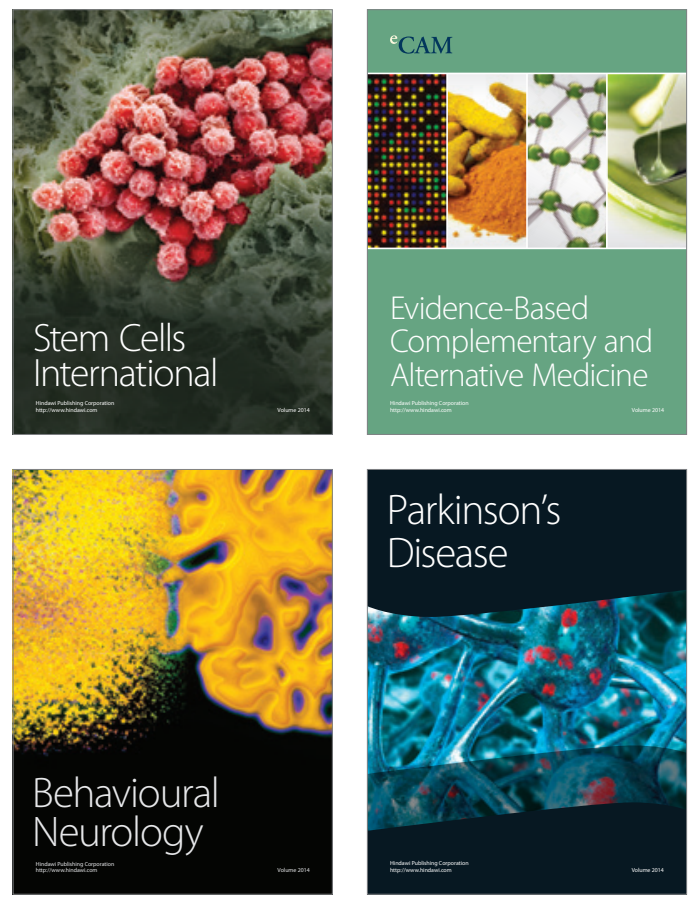
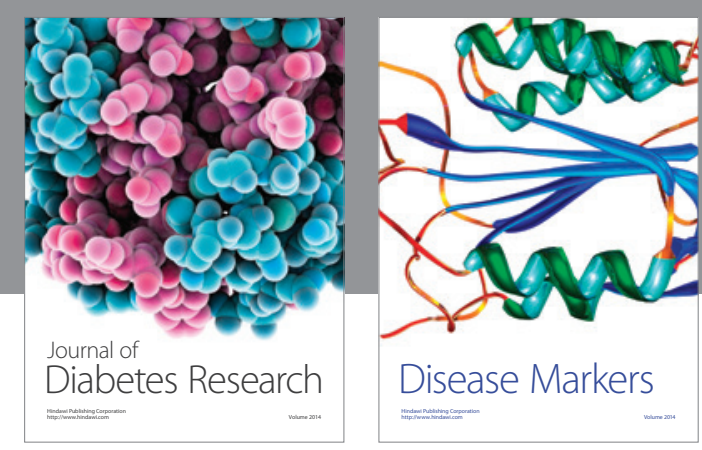

Disease Markers
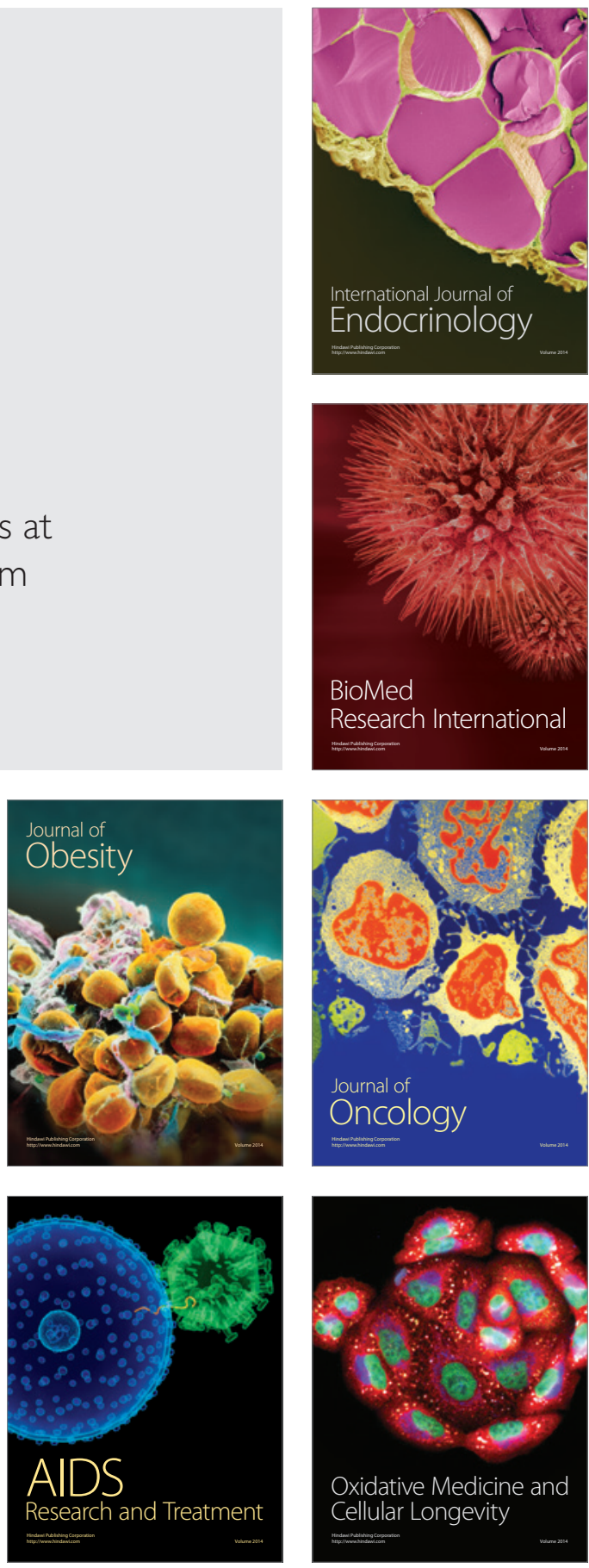